\title{
A case study to prepare for the utilization of aerosol forecasts in solar energy industries
}

\author{
H. Breitkreuz ${ }^{\mathrm{a}, \mathrm{b}, *, 1}$, M. Schroedter-Homscheidt ${ }^{\mathrm{a}, 1}$, T. Holzer-Popp $^{\text {a }}$ \\ ${ }^{a}$ German Aerospace Center (DLR), German Remote Sensing Data Center (DFD), Postfach 1116, 82234 Wessling, Germany \\ b Julius-Maximilian-University Wuerzburg, Department of Geography, Am Hubland, 97074 Wuerzburg, Germany
}

Received 27 July 2005; accepted 16 January 2007

Available online 21 February 2007

Communicated by: Associate Editor David Renne

\begin{abstract}
Precise aerosol information is indispensable in providing accurate clear sky irradiance forecasts, which is a very important aspect in solar facility management as well as in solar and conventional power load prediction. In order to demonstrate the need of detailed aerosol information, direct irradiance derived from Aerosol Robotic Network (AERONET) ground based measurements of aerosol optical depth (AOD) was compared in a case study over Europe to irradiance calculated using a standard aerosol scenario. The analysis shows an underestimation of measurement-derived direct irradiance by the scenario-derived direct irradiance for locations in Northern Europe and an overestimation for the Mediterranean region.

Forecasted AOD of the European Dispersion and Deposition Model (EURAD) system was validated against ground based AERONET clear sky AOD measurements for the same test period of February 15th to 22nd, 2004. For the time period analyzed, the modelled AOD forecasts of the EURAD system slightly underestimate ground based AERONET measurements. To quantify the effects of varying AOD forecast quality in their impact on the application in solar energy industry, measured and forecasted AOD were used to calculate and compare direct, diffuse, and global irradiance. All other influencing variables (mainly clouds and water vapour) are assumed to be modelled and measured correctly for this analysis which is dedicated to the specific error introduced by aerosol forecasting. The underestimated AOD results in a mean overestimation of direct irradiance of $+28 \mathrm{~W} / \mathrm{m}^{2}(+12 \%)$, whereas diffuse irradiance is generally underestimated $\left(-19 \mathrm{~W} / \mathrm{m}^{2}\right.$ or $\left.-14 \%\right)$. Mean global irradiance values where direct and diffuse irradiance errors compensate each other are very well represented (on average $+9 \mathrm{~W} / \mathrm{m}^{2}$ or $+2 \%$ ).
\end{abstract}

(c) 2007 Elsevier Ltd. All rights reserved.

Keywords: Irradiance forecast; Aerosols; Direct and diffuse irradiance; Air quality modelling

\section{Introduction}

Depletion of the supplies of fossil fuels have led to growing activities aimed at promoting alternative power supply

\footnotetext{
* Corresponding author. Address: German Aerospace Center (DLR), German Remote Sensing Data Center (DFD), Postfach 1116, 82234 Wessling, Germany. Tel.: +49 815328 1334; fax: +49 8153281363 .

E-mail address: Hanne-Katarin.Breitkreuz@dlr.de (H. Breitkreuz).

${ }^{1} \mathrm{H}$. Breitkreuz and M. Schroedter-Homscheidt are member of the Helmholtz society (HGF) Virtual Institute of Energy Meterology (vIEM).
}

systems. One such strategy is to raise the effectiveness of renewable energy production, which needs a thorough integration of these highly variable alternative power sources into existing conventional power supply systems. For the solar energy sector this is only possible if reliable shortterm predictions of direct and global solar irradiance can be obtained.

So far, irradiance information has mostly been available as retrospective time series, used by the solar energy industry for site auditing and facility monitoring. But in addition, near-real-time forecasts of direct and global solar irradiance are needed for forecasts of facility yields of 
several hours till up to three days. Only with this information can sensible control and maintenance of solar energy power plants in combination with conventional plants be facilitated.

In addition to air temperature, the amount of available solar irradiance largely determines customer consumption behaviour. Therefore irradiance forecasts are also needed when calculating consumer demands, an essential aspect in controlling both traditional and solar energy power plants.

In order to calculate direct and global irradiance at surface level, exact information about clouds, aerosols, water vapour and ozone is needed. For overcast skies, knowledge of cloud cover and type is most important in determining irradiance values. Cloud cover information is also important for distinguishing between overcast and clear situations. In the clear sky case, however, precise aerosol information is indispensable for providing accurate irradiance forecasts since up to $20-30 \%$ of direct irradiance losses have been reported for cases of high particle occurrence (e.g., Henzing et al., 2004; Jacovides et al., 2000; Latha and Badarinath, 2005). That fact that there is a focus of the solar energy industry on relatively cloud-free regions, e.g. the Mediterranean area, explains why clear sky calculations are of great relevance for irradiance forecasts. Therefore, the paper focuses on the analysis of clear sky cases only.

Contrary to the gas phase species involved in atmospheric extinction, not only substance concentrations are needed for assessing the influence of atmospheric particles on solar irradiance: spectral extinction gradients and scattering/absorption ratios can only be determined when additional aerosol type information is provided. These comparatively complicated data requirements and a large spatial and temporal variability (Anderson and Charlson, 2003) explain why most operational irradiance forecast systems still rely on standard aerosol scenarios or roughly structured climatologies based on monthly mean values on a 4 or 5 degree geographical grid (e.g., Kinne et al., 2005) instead of including exact forecasts of aerosol load. For example, global irradiance forecasts of the European Centre for Medium-Range Weather Forecasts (ECMWF) are calculated using an aerosol climatology containing annual AOD cycles for four tropospheric aerosol types (ECMWF, 2004). A comparison of various atmospheric extinction model approaches used for irradiance calculation can be found in Hammer (2000). Here regionally structured classes of turbidity factors or standard aerosol scenarios are used to calculate atmospheric extinction within clear sky models. However, in the clear sky case these simplified approaches are not sufficient to account for the highly variable influence of atmospheric particles on solar irradiance (e.g., Gueymard, 2003). A study by Olmo et al. (2001) quantifies the effect of using a monthly AOD climatology with a fixed spectral extinction gradient instead of measured aerosol parameters: this leads to a RMSE of $11.4 \%$ instead of $2.9 \%$ in modelled direct irradi- ance and $52.3 \%$ instead of $32.1 \%$ for modelled diffuse irradiance, compared with one-minute averages of clear sky irradiance measurements.

This paper assesses the accuracy of a chemical transport model to obtain aerosol information for irradiance forecasts. A period of eight days, from February 15th to 22nd 2004, was chosen for this study. During the last two days a dust storm outbreak, reaching from the Saharan desert into central Mediterranean regions, caused extremely high particle loads. However, the separate analysis of this period with unusually high AOD values failed, due to limitations in cloud screening procedures of the AERONET ground measurements.

Section 2 presents the data used for the analysis and Section 3 specifies the radiative transfer algorithms and auxiliary data used. The importance of detailed aerosol information for calculating direct irradiance is assessed in Section 4.1. Forecasted AOD of the EURAD system are validated with ground-based AERONET measurements in Section 4.2 and in Section 4.3 the influence of forecasted AOD on irradiance forecasts is analysed.

\section{The data sources}

\subsection{The EURAD forecast system}

The EURopean Air Pollution Dispersion (EURAD) model encorporates physical, chemical and dynamical processes related to emission, transport and deposition of atmospheric substances (Hass et al., 1995). The EURAD model was developed for air quality research purposes by members of the Rhenish Institute of Environmental Research (RIU) at the University of Cologne and operationally provides particle occurrence and air quality forecasts (http://www.eurad.uni-koeln.de).

The main elements of the system are three sub-models treating meteorological input (NCAR: MM5 mesoscale model) (Grell et al., 1994), emission data (Memmesheimer et al., 1995) and a chemical transport model (Hass et al., 1995). Aerosol processes are accounted for within an additional MADE sub-system (Modal Aerosol Dynamic Model), which includes particle emission, coagulation and growth, transport, wet and dry deposition (Ackermann et al., 1998).

The complete system yields mass concentrations of all treated species in three different size modes (nucleation, accumulation and coarse), differentiating among 23 tropospheric height levels. Primary organic material and elemental carbon, sulphate, ammonium, nitrate, "not identified" anthropogenic particulate matter and aerosol liquid water are considered in accumulation and nucleation mode. Anthropogenic aerosols are additionally included as coarse mode particles. Secondary organic substances are treated by the SORGAM module (Secondary ORGanic Aerosol Model) (Schell et al., 2001). Integration of natural coarse mode particles - sea salt, dust - is in preparation. The nesting capability of the model system enables various grid 
sizes for the coverage of regions as North Rhine-Westphalia, Germany, Europe or the Northern Hemisphere, depending on the region of interest. The European nest has a resolution of $125 \times 125 \mathrm{~km}$ and was used in this study to cover Europe including the African Mediterranean coastal areas.

As standard output particle mass concentrations of different aerosol species are usually combined to produce single $\mathrm{PM}_{10}$-values (total mass concentration of particles smaller than $10 \mu \mathrm{m}$ at the surface). In the case study presented, however, separate mass concentration values of all substances modelled are used in order to calculate vertically integrated AOD values.

For all substances and size distributions, extinction coefficients are calculated separately, using a fast Mie extinction parameterisation (Evans and Fournier, 1990). Extinction coefficients $\sigma_{\text {ext }}$ are then vertically integrated through all height layers to produce aerosol optical depth values for each grid point, where AOD is defined as:

$\delta=\int_{0}^{\mathrm{H}} \sigma_{\text {ext }}(h) \mathrm{d} h \quad \mathrm{H}=$ model $/$ troposphere top

Note that AOD is dimensionless. In accordance with most studies regarding the influence of aerosols on solar radiation, AOD values presented in this paper are given at a wavelength of $550 \mathrm{~nm}\left(\mathrm{AOD}_{550}\right)$. For the study eight forecast runs were analysed, starting at midnight each day from Feb 15th to 22nd 2004. Each forecast run has a temporal resolution of one hour and lasts three days, so that for each grid point a total of 72 values are available.

\subsection{AERONET validation data}

Validation of the modelled aerosol optical depth values was performed using AERONET (AErosol RObotic NETwork) ground-based sun photometer measurements (Holben et al., 1998). The NASA-operated AERONET program was established to gather aerosol information and provide validation data for satellite retrievals of aerosol optical properties. Datasets are available at http://aeronet.gsfc.nasa.gov and contain AOD measurements at nine different wavelengths at 1020, 870, 670, 535, 532, $500,440,380$ and $340 \mathrm{~nm}$ as well as solar zenith angles, total water vapour column measurements and several variability coefficients used for automatic cloud screening procedures.

In this study, all ground stations in Europe providing level 1.5 data (automatically cloud screened measurements) during the example period from Feb 15th to 22nd 2004 were considered. This led to a sum of 24 ground stations with a total of 1541 measurements to be included in the analysis described. Table 1 presents a complete list of all stations including information about the number of measurements available, each station's mean AOD550 and corresponding variability information.
Table 1

Station mean values for $\mathrm{AOD}_{550}$, its standard deviation $\sigma$, the number of included measurements $n$ and geographical coordinates (in order of ascending latitude)

\begin{tabular}{lllrrl}
\hline Station & AOD $_{550}$ & \multicolumn{1}{l}{$\sigma$} & \multicolumn{1}{c}{ Lon $\left[{ }^{\circ} \mathrm{E} / \mathrm{W}\right]$} & Lat $\left[{ }^{\circ} \mathrm{N}\right]$ \\
\hline Crete & 0.16 & 0.04 & 33 & 25.28 & 35.33 \\
Lampedusa & 0.13 & 0.04 & 60 & 12.63 & 35.52 \\
Blida & 0.36 & 0.19 & 30 & 2.88 & 36.51 \\
El Arenosillo & 0.26 & 0.11 & 120 & -6.73 & 37.11 \\
Evora & 0.17 & 0.07 & 74 & -7.91 & 38.57 \\
Cabo da Roca & 0.15 & 0.13 & 29 & -9.05 & 38.78 \\
Lecce & 0.13 & 0.07 & 77 & 18.10 & 40.33 \\
Rome & 0.16 & 0.10 & 75 & 12.65 & 41.84 \\
Palencia & 0.20 & 0.11 & 70 & -4.52 & 41.99 \\
Toulouse & 0.23 & 0.17 & 21 & 1.37 & 43.58 \\
Villefranche & 0.31 & 0.14 & 133 & 7.33 & 43.68 \\
Avignon & 0.24 & 0.12 & 57 & 4.88 & 43.93 \\
Carpentras & 0.32 & 0.20 & 69 & 5.06 & 44.08 \\
Venice_Adria & 0.45 & 0.22 & 120 & 12.51 & 45.31 \\
Venice & 0.47 & 0.15 & 79 & 12.33 & 45.44 \\
Ispra & 0.72 & 0.20 & 66 & 8.63 & 45.80 \\
Kishinev & 0.10 & 0.04 & 105 & 28.82 & 47.00 \\
Mainz & 0.13 & 0.02 & 79 & 8.30 & 50.00 \\
Leipzig & 0.11 & 0.02 & 2 & 12.44 & 51.35 \\
Belsk & 0.08 & 0.03 & 16 & 20.79 & 51.84 \\
Mace Head & 0.05 & 0.02 & 40 & -9.90 & 53.33 \\
Hamburg & 0.07 & 0.06 & 115 & 9.97 & 53.57 \\
Moscow & 0.13 & 0.04 & 48 & 37.51 & 55.70 \\
Toravere & 0.05 & 0.02 & 23 & 26.46 & 58.26 \\
\hline
\end{tabular}

\section{Radiative transfer calculations and auxiliary data}

All radiative transfer calculations described in this paper were performed with the program libRadtran (library for Radiative transfer) (Mayer and Kylling, 2005). This system consists of various radiative transfer routines and is available at http://www.libradtran.org. Its main routine, uvspec, calculates direct and global spectral irradiance at surface level, taking into account atmospheric multiple scattering and absorption as well as surface properties. A fast 27band correlated- $k$ approximation was chosen, calculating the incoming irradiance in 27 adjacent intervals comprising wavelengths from 300 to $3000 \mathrm{~nm}$. Each interval spans between 6 and $65 \mathrm{~nm}$ in the visible range with progressively larger intervals towards the near infrared. Solar radiation and all atmospheric properties considered (e.g. Rayleigh scattering, molecular absorption, ice and water clouds, aerosol properties and surface albedo) can be incorporated by standard configurations provided by the program or partly or totally substituted by user-defined values.

For all clear sky irradiance calculations evaluating the EURAD forecast system in Section 4.3 total water vapour columns have been taken from measurements provided by the Advanced TIROS Operational Vertical Sounder (ATOVS) instrument aboard the National Oceanic and Atmospheric Administration (NOAA) satellite (available at http://wdc.dlr.de/data_products). If daytime measurements of NOAA-16 were available for the date and location needed, these values were used, otherwise NOAA-14 measurements were taken. In case both daytime orbits 
failed to cover one of the ground stations considered, a fixed value of $15 \mathrm{~mm}$ total water vapour column was substituted. The latter value was also used for all irradiance calculations of the sensitivity study described in Section 4.1. A typical mean value of $15 \mathrm{~mm}$ was chosen for Europe also to ensure comparability with a study result performed during the EU-funded project Heliosat-3 (Heliosat-3, 2001) which deals with enhanced surface irradiance calculations by using the Meteosat Second Generation (MSG) satellite. Compared to atmospheric model analysis data of the European Centre for Medium-Range Weather Forecasts (ECMWF) operational archive, NOAA-16-ATOVS total water vapour column retrievals have a mean bias of $-1.71 \mathrm{~mm}$ and a RMSE of $5.32 \mathrm{~mm}$ for February 2004 . NOAA-14 measurements account to a mean bias of $+1.97 \mathrm{~mm}$ and a RMSE of $4.76 \mathrm{~mm}$ for the same month.

Ozone column values and ground albedo information were set to constant values (275 DU and 0.1, respectively) to again facilitate comparability with study results achieved during the Heliosat-3 project. Since the analysis is performed for spectrally integrated irradiance values from 300 to $3000 \mathrm{~nm}$ only, the irradiance calculation errors caused by the use of a fixed ozone value are negligible. For calculations realised with a fixed water vapour value, the absorption bands in the near infrared can lead to an error in irradiance calculation, as can the substitution of a fixed value for ground albedo information, even though the effect will be diminished by spectral integration. In addition, it should be noted that fixed values for ozone and water vapour (if no satellite data is available) are always used for both the observations-based and the model-based irradiance calculation of corresponding days and hours so that relative ratios of direct, diffuse and global radiation remain mainly untouched by possible deviations in input parameters. Due to non-linearity this is not the case for deviations in surface albedo. However, also for ground albedo information fixed values are used as this will only cause second order deviations.

Aerosol information, the parameter under investigation, was obtained either from AERONET measurements $\left(\mathrm{AOD}_{550}\right.$, Angstrom coefficients), the EURAD system $\left(\mathrm{AOD}_{550}\right)$ or a standardized aerosol scenario developed after Shettle (1989).

\section{Results}

The analysis described in Section 4.1 demonstrates the importance of detailed aerosol information for clear sky irradiance calculations. For this sensitivity study direct irradiance derived from AERONET ground based measurements of aerosol optical depth (AOD) was compared to irradiance calculated using a standard aerosol scenario.

In Section 4.2 forecasted AOD of the EURAD system was validated against ground based AERONET AOD measurements. To quantify the effects of varying AOD in their impact on the application in solar energy industry, measured and forecasted AOD were used to calculate and compare direct, diffuse and global irradiance values (see Section 4.3).

\subsection{Assessment of the importance of detailed aerosol information}

Direct irradiance derived from AERONET ground based AOD measurements between February 15th and 22nd 2004, was compared to irradiance calculated using the standard aerosol scenario described below.

For the case study presented a total of 1541 level 1.5 AERONET ground measurements were available (see Table 1). For each measurement $\mathrm{AOD}_{550}$ was linearly interpolated from AOD values at wavelengths of $500 \mathrm{~nm}$ and $670 \mathrm{~nm}$ or 440 and $670 \mathrm{~nm}$, if $500 \mathrm{~nm}$ values were not available. This simplification can be justified for most situations since the deviation of interpolated $\mathrm{AOD}_{550}$ values in comparison to exact calculations with a power law specified by Angstrom coefficients is lower than 0.01/0.05 absolute $\mathrm{AOD}_{550}$ for low/medium aerosol conditions $\left(\mathrm{AOD}_{550}\right.$ of $\left.0.15 / 0.35\right)$. However, it should be noted that for very polluted situations $\left(\mathrm{AOD}_{550}>1.0\right.$, occurred in $1 \%$ of the cases during the time period analysed) the error in absolute $\mathrm{AOD}_{550}$ due to this simplification can be as high as 0.15 and thus exceed accuracy requirements.

$\mathrm{AOD}_{550}$ values and Angstrom coefficients were used as aerosol specification in the calculation of direct irradiance values with libRadtran. Solar zenith angle data and calendar date were included as well from the corresponding AERONET files and additional input information comprised of fixed water vapour column $(15 \mathrm{~mm})$, ozone (275 DU) and ground albedo (0.1) values.

All calculations were repeated for a second time with the same atmospheric specifications, with the change that aerosol information was replaced with a standard aerosol scenario. The aerosol scenario chosen is part of the libRadtran standard settings and is defined by the following assumptions: rural aerosol type for up to $2 \mathrm{~km}$ height, stratospheric aerosol background type, spring/summer conditions and $50 \mathrm{~km}$ visibility in the boundary layer (Shettle, 1989).

For each measurement an irradiance ratio $R_{\mathrm{dir}}$ was computed which is defined as the scenario-derived direct irradiance $I_{\text {dir }}$ (scenario) divided by the AERONET measurement-derived direct irradiance $I_{\mathrm{dir}}$ (observation):

$R_{\mathrm{dir}}=\frac{I_{\mathrm{dir}}(\text { scenario })}{I_{\mathrm{dir}}(\text { observation })}$

In Fig. 1 mean values of this direct irradiance ratio $R_{\text {dir }}$ are shown for all stations in order of ascending latitude. The vertical lines indicate the variability of $R_{\text {dir }}$ for each station, comprising the interval of \pm 1 standard deviation of the corresponding station's ratio $R_{\text {dir. }}$. The analysis shows an underestimation of measurement-derived direct irradiance by the standard setup-derived direct irradiance of up to $-23 \%$ for locations in Northern Europe (e.g. Mace 


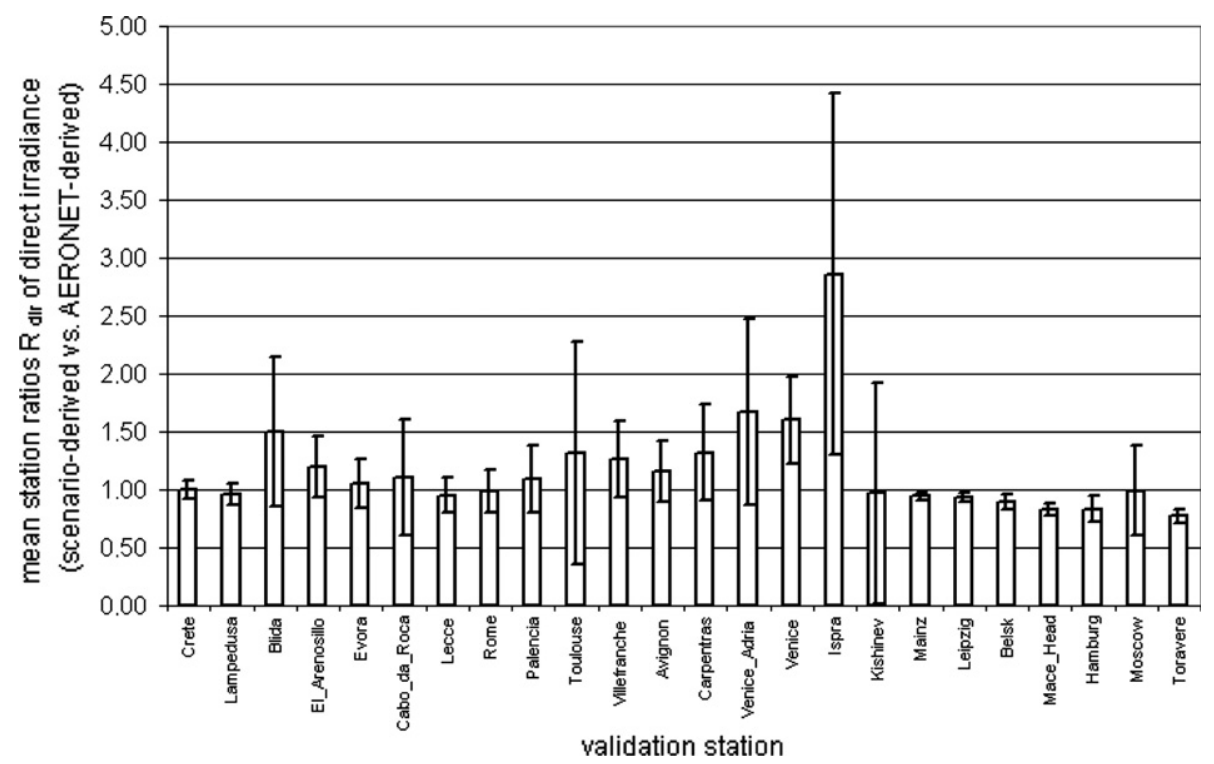

Fig. 1. Mean station values of direct irradiance ratios $R_{\text {dir }}$ : scenario-derived divided by AERONET-derived irradiance; single lines indicate \pm 1 standard deviation.

Head, Toravere) and an overestimation of up to $+60 \%$ (e.g. Venice), in extreme cases $+290 \%$ (Ispra), for the Mediterranean region. Generally the standard scenario overestimates aerosol amount in the Northern and Central parts of Europe, whereas particle concentrations in the Mediterranean area are mostly underestimated.

This general regional trend is varied by a broad spatial and temporal variability, especially in the Southern regions of the area considered. For example, the standard deviation of irradiance ratio $R_{\mathrm{dir}}$ is highest in Venice_Adria, Toulouse and Ispra which results in a very large range of errors. This means that for these locations it is extremely difficult to assess the error committed when using a standard aerosol setting instead of measurements for irradiance calculations. However, the Mediterranean area presents a main focus of the solar energy industry. This places emphasis on the importance of accurate regional aerosol forecasts when calculating irradiance, since the high temporal and spatial variability of particle distribution (Anderson and Charlson, 2003) can lead to significant errors in irradiance information.

\subsection{Evaluation of $A O D$ forecasts}

For the same time period (Feb 15th to 22nd 2004) and the same stations forecasted particle mass concentrations of the EURAD-MADE system were converted to $\mathrm{AOD}_{550}$ and validated against AERONET measurements. For each AERONET ground measurement $\mathrm{AOD}_{550}$ was linearly interpolated from adjacent wavelengths at $500 \mathrm{~nm}$ and $670 \mathrm{~nm}$ (see Section 4.1). For some stations the $500 \mathrm{~nm}$ measurement was not available, and the $670 \mathrm{~nm}$ and $440 \mathrm{~nm}$ AOD values were used instead. Hourly station means $\left(t_{0} \pm 30 \mathrm{~min}\right)$ were calculated to produce temporal mean values. In contrast, the EURAD system provides instantaneous values for each full hour. Nevertheless, comparability of the two datasets is improved by the fact that spatially averaged values for one point in time (EURAD system) are compared with temporally averaged $\mathrm{AOD}_{550}$ values for one location (AERONET) within the corresponding EURAD grid box.

For absolute AOD differences, AERONET AOD ${ }_{550}$ values were subtracted from the $\mathrm{AOD}_{550}$ value of the closest EURAD grid point for all corresponding days and hours. Since most of the ground stations involved have very low AOD values (see Table 1), relative differences in AOD were not evaluated.

The distribution of all differences in $\mathrm{AOD}_{550}$ for the period considered is shown in Fig. 2. It can be summarized that the modelled AOD forecasts of the EURAD-MADE

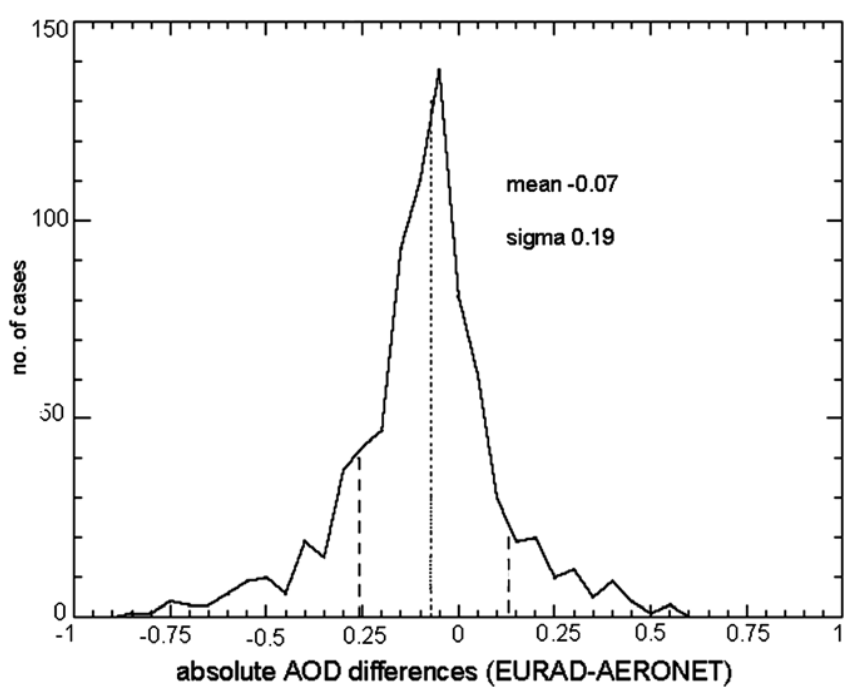

Fig. 2. Distribution of absolute AOD differences (EURAD-AERONET). 


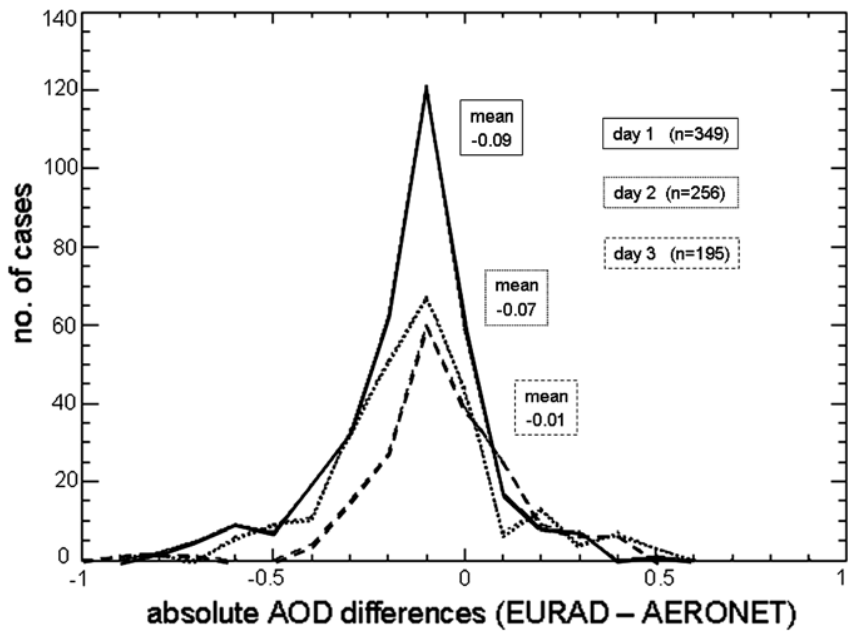

Fig. 3. Distribution of absolute AOD differences (EURAD-AERONET), separated into three classes of forecast length with one (solid line), two (dotted line) and three (dashed line) days.

system slightly underestimate ground based AERONET measurements of aerosol optical depth by a mean of 0.07 . In more than half of the cases considered, absolute differences in $\mathrm{AOD}_{550}$ are within 0.1 of this mean difference. The standard deviation accounts to 0.19 .

One main issue was to assess the accuracy of the modelled AOD with respect to forecast length. To investigate this, absolute AOD differences were differentiated into three time classes with respect to forecast length. Fig. 3 shows the distribution of all differences calculated during the first (solid line), the second (dotted line) and the third day (dashed line) of each forecast run. Due to inequalities in the total daily sums of the available AERONET ground measurements, the amount of data considered varies greatly within those three classes. This prevents a more detailed conclusion regarding forecast accuracy as it relates to forecast length until longer episodes of data have been analysed. Nevertheless, it can be summarized that no interrelation between forecast accuracy and duration of forecast is apparent in this case study, neither in RMSE nor in bias values.

To assess regional variability within the area included in the analysis, mean absolute differences in AOD were calculated separately for each validation station. Fig. 4 shows the mean values of absolute AOD differences and the corresponding standard deviation for each station. In the Northern and Central parts of Europe modelled AOD generally yields quite good estimates of observed AOD (e.g. Hamburg) or overestimations (e.g. Toravere, Estonia) of AOD, whereas underestimations by the EURAD-MADE model are predominant in strongly polluted areas in Northern Italy (e.g. Ispra or Venice). Especially in the Mediterranean area a significant spatial and temporal variability can be detected, which overlaps with the general tendencies found in Section 4.1. For single stations (e.g. Ispra, Villefranche, Cabo da Roca) the variability of forecast quality is quite high. This can partly be explained by the limited time period of only eight days covered by this case study.

A further point of interest was forecast accuracy against time of day. Mean values were calculated for all absolute AOD differences for each hour during daylight period between 6 a.m. and 17 p.m. However, the dataset analysed showed no dependence on time of day, neither regarding mean absolute differences nor in error variability, which is a promising result for applications of the methodology.

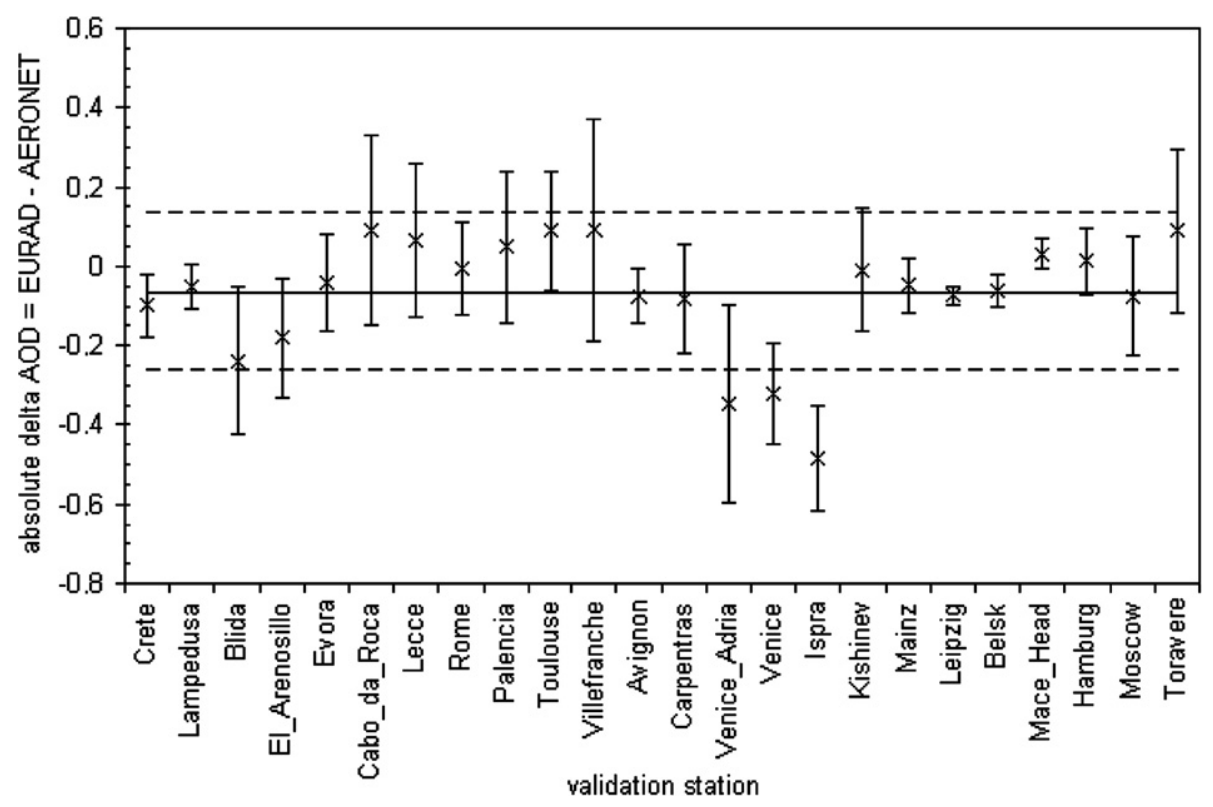

Fig. 4. Mean values per station of absolute AOD differences (EURAD-AERONET), in geographical order, vertical lines indicate mean difference \pm 1 standard deviation. 
4.3. Assessment of the influence of aerosol optical depth forecasts on solar irradiance forecasts

To quantify the effects of varying AOD forecast quality in their impact on the application of irradiance forecasts in the solar energy industry, AERONET-measured and EURAD-forecasted AOD from 4.2 were used to calculate and compare direct, diffuse and global irradiance. Again libRadtran was used to perform the radiative transfer calculations for each of the AERONET ground measurements considered, using the measured aerosol information, solar zenith angle and date information as calculation input. In agreement with the analysis described in Section 4.1, ozone and ground albedo information were assumed as constant values. The resulting direct, diffuse, and global irradiance values were then averaged to hourly means for direct comparison with EURAD-derived spectrally integrated irradiance. The latter irradiance calculations were carried out with the same atmospheric parameters, only aerosol information was substituted by the $\mathrm{AOD}_{550}$ values derived from the EURAD model.

All irradiance values were spectrally integrated (300$3000 \mathrm{~nm}$ ) and then absolute differences in direct, diffuse, and global irradiance were calculated by subtracting AERONET-derived irradiance from the corresponding EURAD-derived irradiance. Relative differences were calculated by normalising absolute differences in irradiance with the corresponding station mean of AERONETderived irradiance.

The distribution of absolute differences in global, direct and diffuse irradiance is shown in Fig. 5. As suggested by the distribution of absolute differences in AOD which demonstrates a slight AOD underestimation by the EURAD model (see Fig. 2), diffuse irradiance values are underestimated by an average of $19 \mathrm{~W} / \mathrm{m}^{2}$. Direct irradiance is accordingly overestimated by a mean of $28 \mathrm{~W} / \mathrm{m}^{2}$. Global irradiance values where direct and diffuse irradiance errors compensate each other are very well represented $(+9 \mathrm{~W} /$

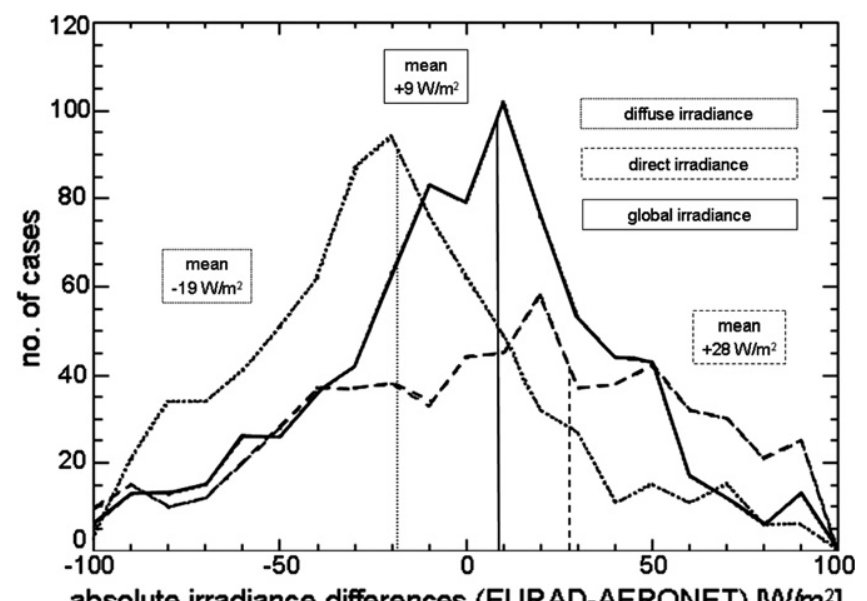

Fig. 5. Distribution of absolute differences (EURAD-AERONET) of diffuse, direct, and global irradiance $\left[\mathrm{W} / \mathrm{m}^{2}\right]$.

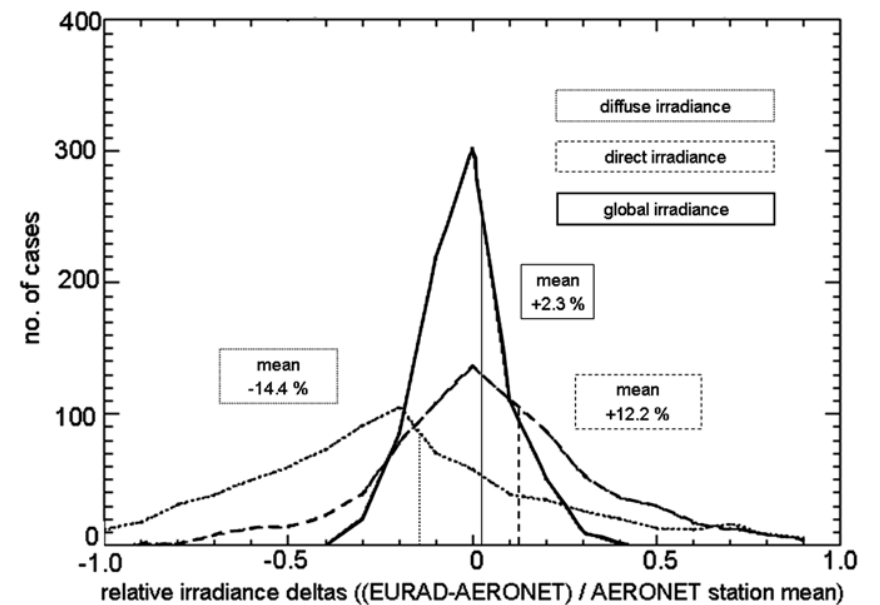

Fig. 6. Distribution of mean relative differences (EURAD-AERONET)/ AERONET per station of diffuse, direct, and global irradiance.

$\mathrm{m}^{2}$ ). Fig. 6 presents the corresponding relative distributions of irradiance with mean differences of $-14 \%$ for diffuse, $+12 \%$ for direct, and $+2 \%$ for global irradiance.

Analogous to AOD difference analysis, the distribution of irradiance differences with respect to the ground stations involved was assessed. Fig. 7 shows the ratio of EURADderived direct irradiance to AERONET-derived direct irradiance in geographical order of the ground stations included. Single lines indicate the variability of the station ratios ( \pm 1 standard deviation). Here a slight dependence on regional characteristics is again obvious: the ratio of modelled and measured AOD in Northern Europe mostly yields underestimation of direct irradiance, whereas the situation in the strongly polluted areas in Northern Italy is generally the opposite.

However, in several single locations (e.g. Ispra, Villefranche, Cabo da Roca) a large spatial and temporal variability of $R_{\text {dir }}$ overlaps with these tendencies found, as expected from the results of the analysis of absolute AOD differences described in Section 4.2. This again reinforces the strong requirement of the solar energy sector for high resolution aerosol information such as from the EURAD forecast system when calculating irradiance forecasts. At the same time, it suggests the urgent need to include larger amounts of data in the analysis in order to be able to differentiate between small scale variabilities and more dominant spatial and temporal dependencies.

\section{Discussion}

The need for accurate and detailed aerosol information was clearly demonstrated by a case study over Europe comparing direct irradiance values derived from AERONET ground measurements and from a standard aerosol scenario. The analysis of a test period from February 15th to 22nd 2004 shows an underestimation of measurementderived direct irradiance by the scenario-derived direct irradiance for locations in Northern Europe of up to $-23 \%$ 


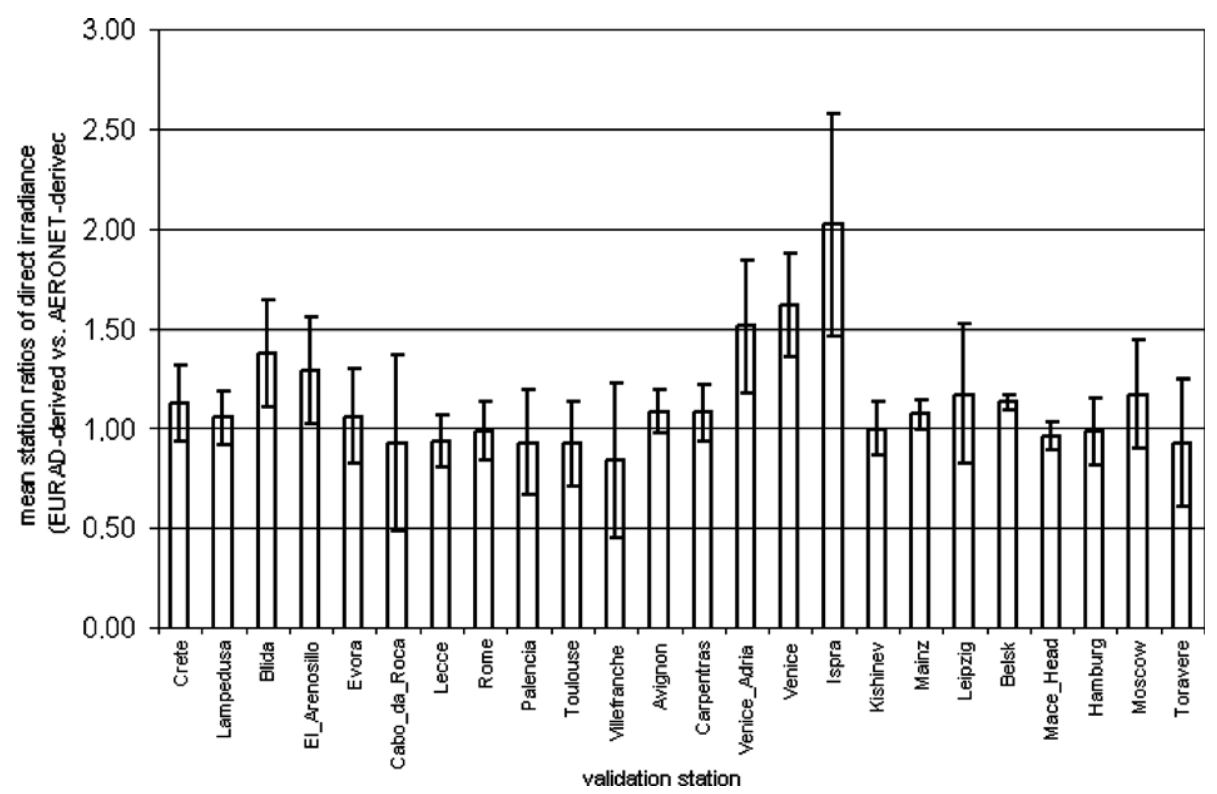

Fig. 7. Mean station values of direct irradiance ratios: EURAD-derived divided by AERONET-derived irradiance; single lines indicate \pm 1 standard deviation.

and an overestimation for the Mediterranean region of up to $+60 \%$, in extreme cases even $+290 \%$, for the study period.

The accuracy of aerosol forecasts from the EURAD model system was validated against AERONET ground based AOD measurements. For the time period analysed the modelled AOD forecasts of the EURAD system slightly underestimate ground based AERONET measurements by 0.07 . No error dependence on forecast length could be determined.

The impact of a Saharan dust storm reaching into central Mediterranean regions during the last two days of the period chosen for this study could not be analysed, due to limitations in automatic cloud detection procedures for the level 1.5 AERONET data used. It must be concluded that not only the EURAD model - due to still ongoing procedures to integrate dust and sea salt particles into the forecast system - but also ground measurement systems are very much restricted in assessing these special high aerosol load occasions.

To quantify the effects of varying AOD in their impact on the application of irradiance forecasts in the solar energy industry, measured and forecasted AOD were used to calculate and compare clear sky direct, diffuse, and global irradiance. The AOD deviations in this test case result in a mean overestimation of direct irradiance of $+28 \mathrm{~W} / \mathrm{m}^{2}$ $(+12 \%)$, whereas diffuse irradiance is generally underestimated $\left(-19 \mathrm{~W} / \mathrm{m}^{2}\right.$ or $\left.-14 \%\right)$. Mean global irradiance values where direct and diffuse irradiance errors compensate each other are very well represented (on average $+9 \mathrm{~W} /$ $\mathrm{m}^{2}$ or $+2 \%$ ). This mean bias value of global irradiance is within currently accepted deviations for irradiance model performance. For example, a study by Gueymard (2003) concludes for a series of comparisons of broadband atmospheric transmission models against the well-described ref- erence model MODTRAN (Moderate Resolution Transmittance Code) a bias of $5 \%$ and a RMSE of $8 \%$ to be excellent. The bias of direct and diffuse irradiance, however, is significantly larger than for global irradiance differences and exceeds these accuracy requirements. These deviations can partly be explained by the high solar zenith angles predominant in the February episode chosen for this study (ranging from $45^{\circ}$ to $80^{\circ}$, mean $66^{\circ}$ ), which significantly increase the impact of aerosols on direct and diffuse irradiance values. Consequently further improvement in aerosol data quality is strongly desirable, as turbidity information - especially in cases of low solar elevation accounts for the largest errors in clear sky irradiance forecasts (van Weele et al., 2000; Gueymard, 2005).

In combination with the large spatial and temporal variability encountered in aerosol optical depths, evaluation of a longer time series of data should therefore be pursued in order to achieve quantitatively reliable validation results also for single values and also as a function of forecast length, season and regional specialities. Consequently analysis of longer study periods is in preparation which will at the same time evaluate the need for possible adjustments of regional emission data in the EURAD model system. Progress in forecast quality will also be achieved by the planned incorporation of modules for transported mineral dust and sea salt particles into the model system. Further plans include the assimilation of satellite-based aerosol information into the EURAD air quality forecast model, to be accomplished within the DFG-project AERO-SAM (Boundary layer AEROsol characterization from Space by advanced data Assimilation into a tropospheric chemistry transport Model).

Additional improvements in evaluation results are expected by a more accurate calculation of $\mathrm{AOD}_{550}$ from AERONET data (see Section 4.1) and an expansion of this 
analysis to spectrally resolved irradiance values. This includes the use of more exact input parameters for radiative transfer calculations, e.g. measured or modelled ozone and ground albedo data instead of fixed average values.

Despite the necessary improvements in model design and analysis described above, these first case study results justify the approach and document the strong need for using a chemical transport model designed for air quality research as basis for a 1-3 day solar irradiance forecasting system for solar energy industry purposes.

\section{Acknowledgements}

We thank members of the EURAD-Team at the University of Cologne/Rhenish Institute for Environmental Research, especially Hendrik Elbern, Elmar Friese and Michael Memmesheimer, for providing generous amounts of data. We thank the AERONET Principal Investigators and their staff for establishing and maintaining the 24 sites used in this investigation. We also thank Bernhard Mayer and Arve Kylling, whose radiative transfer program libRadtran has been used for all irradiance calculations. We appreciate the valuable comments of three anonymous reviewers.

The conversion tool used for calculating AOD from particle mass concentrations was developed within the DFG project AERO-SAM (Boundary layer AEROsol characterization from Space by advanced data Assimilation into a tropospheric chemistry transport Model) at DLR-DFD and the University of Cologne and will be published in a separate study.

This work was funded by the Virtual Institute of Energy Meteorology - supported by the "Impuls- und Vernetzungsfond" of the Helmholtz Association of National Research Centers - and by the EU-funded Project Heliosat-3 (No. NNE5-2000-00413, see Heliosat-3 (2002)).

\section{References}

Ackermann, I.J., Hass, H., Memmesheimer, M., et al., 1998. Modal aerosol dynamics model for europe: development and first applications. Atmospheric Environment 32 (17), 2981-2999.

Anderson, T.L., Charlson, R.J., 2003. Mesoscale variations of tropospheric aerosols. Journal of the Atmospheric Sciences 60, 119-136.

European Centre of Medium-Range Weather Forecasts (ECMWF), 2004. IFS Documentation CY28r1. IV. Physical Processes, 2.5 Input to the radiation scheme. <http://www.ecmwf.int/research/ifsdocs/CY28r1/ Physics/Physics-03-6.html $>$.

Evans, B.T.N., Fournier, G.R., 1990. Simple approximation to extinction efficiency valid over all size parameters. Applied Optics 29 (31), 46664670.

Grell, A., Dudhia, J., Stauffer, D.R., 1994. A description of the fifth generation Penn State/NCAR Mesoscale Model (MM5). NCAR Technical Note, NCAR/TN-398+STR.
Gueymard, C.A., 2003. Direct solar transmittance and irradiance predictions with broadband models. Part II: validation with high-quality measurements. Solar Energy 74 (5), 381-395.

Gueymard, C.A., 2005. Importance of atmospheric turbidity and associated uncertainties in solar radiation and luminous efficacy modelling. Energy 30, 1603-1621.

Hammer, A., 2000. Anwendungsspezifische Solarstrahlungsinformationen aus Meteosat-Daten. Diss., Universitaet Oldenburg.

Hass, H., Jakobs, H., Memmesheimer, M., 1995. Analysis of a Regional Model (EURAD) near surface gas concentration predictions using observations from networks. Meteorology and Atmosphere Physics 57, 173-200.

Heliosat-3 Consortium, 2001. Energy-specific solar radiation data from Meteosat Second Generation (MSG): The Heliosat-3 Project. Compilation of data requirements, EC FP 5 Project No. NNE52000-00413.

Heliosat-3 Consortium, 2002. Energy-specific solar radiation data from Meteosat Second Generation (MSG): The Heliosat-3 Project. Midterm progress report, EC FP 5 Project No. NNE5-2000-00413. $<$ http://www.heliosat3.de/documents $>$.

Henzing, J.S., Knap, W.H., Stammes, P., 2004. Effect of aerosols on the downward shortwave irradiances at the surface: Measurements versus calculations with MODTRAN 4.1. Journal of Geophysical Research 109, D14204.

Holben, B.N., Eck, T.F., Slutsker, I., et al., 1998. AERONET - A federated instrument network and data archive for aerosol characterization. Remote Sensing of Environment 66, 1-16.

Jacovides, C.P., Steven, M.D., Asimakopoulos, D.N., 2000. Spectral solar irradiance and some optical properties for various polluted atmospheres. Solar Energy 69 (3), 215-227.

Kinne, S., Schulz, M., Textor, C., et al., 2005. An aerocom initial assessment - optical properties in aerosol component modules of global models. Atmospheric Chemistry and Physics Discussions 5, 8285-8330.

Latha, K.M., Badarinath, K.V.S., 2005. Spectral solar attenuation due to aerosol loading over an urban area in India. Atmospheric Research 75 (4), 257-266.

Mayer, B., Kylling, A., 2005. Technical note: The libRadtran software package for radiative transfer calculations - description and examples of use. Atmospheric Chemistry and Physics Discussions, 5, 1319-1381.

Memmesheimer, M., Hass, H., Tippke et al., 1995. Modelling of episodic emission data for Europe with the EURAD emission model EEM. In: Ranzieri, A., Solomon, P. (Eds.), Proceedings of the International Speciality Conference Regional Photochemical Measurement and Modelling Studies, 2. Air and Waste Management Association, San Diego, USA, pp. 495-499.

Olmo, F.J., Vida, J., Foyo-Moreno, I., et al., 2001. Performance reduction of solar irradiance parametric models due to limitations in required aerosol data: case of the CPCR 2 model. Theoretical and Applied Climatology 69, 253-263.

Schell, B., Ackermann, I.J., Hass, H., et al., 2001. Modelling the formation of secondary organic aerosol within a comprehensive air quality model system. Journal of Geophysical Research 106 (D22), 28275-28294.

Shettle, E., 1989. Models of aerosols, clouds and precipitation for atmospheric propagation studies. In: AGARD Conference Proceedings NO. 454, "Atmospheric Propagation in the UV, Visible, IR and MM-Region and Related System Aspects".

van Weele, M., Martin, T.J., Blumthaler, M., et al., 2000. From model intercomparison toward benchmark UV spectra for six real atmospheric cases. Journal of Geophysical Research 105 (D4), 49154925 . 